\title{
New Solutions in Radio Wave Surgery - BAE Electrodes
}

\author{
Novak Vukoje ${ }^{1}$ and Jon Garito ${ }^{2}$ \\ ${ }^{1}$ Otorhinolaryngology, Petrovaradin, Serbia \\ ${ }^{2}$ The inovator of new BAERF electrodes, USA
}

Submission: November 09, 2018; Published: November 20, 2018

*Corresponding author: Novak Vukoje, Otorhinolaryngology, Petrovaradin, Serbia

\section{Opinion}

First, the active wire Dr. Garito developed is a ferromagnetic coating over tungsten. It is an excellent conductor of radiofrequency. The new Bio-Active Energy (BAE) RF Electrode alloy possesses a mechanical strength, high resistance, thermal expansion, thermal conductivity, rigidity, and flexibility all at once. It is also biocompatible. With this novel magnetic-resistive wire, the collective oscillation of electrons on the surface causes a phenomenon called surface plasmon resonance. The ferromagnetic layers over the tungsten allows the surface plasmon resonance to attain peak energy, resulting in Bio-Active Energy (BAE), to be manipulated by the free electrons present in the ferromagnetic surface. This layer over the tungsten results in a shift in the peak energy of the surface plasmon. This has just been recognized and published in the Journal of Cardiovascular Electrophysiology / Cardiology Radiofrequency Catheter ablation.
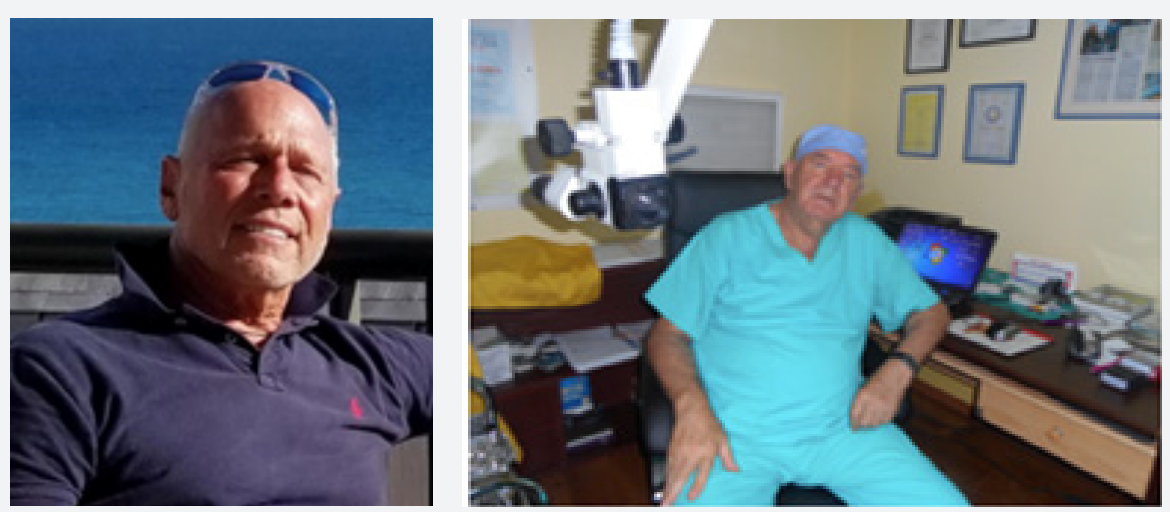

Dr. Jon Garito, an inventor and expert in high frequency radiowave surgery, has worked together with radiowave surgeon Dr. Novak Vukoje to provide the medical \& surgical community with the following information regarding the new Bio-Active Energy (BAE) RF Electrodes.

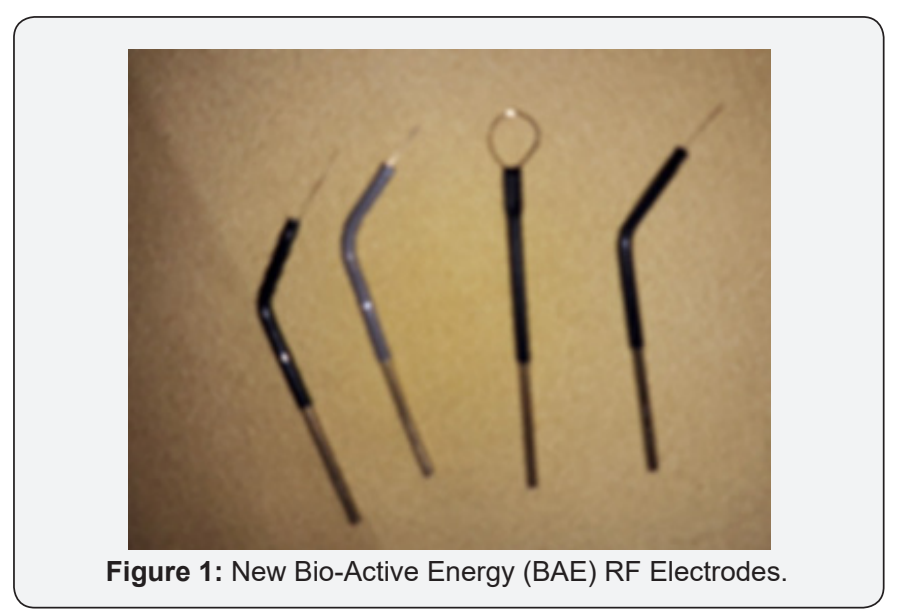

The advantage of this BAE RF electrode, in comparison to the classic electrosurgical electrodes with less energy and strength, is that better surgical outcomes are achieved with less lateral tissue damage, along with creating a minimum thermal lesion and a smaller necrotic field (PHD). Bleeding is minimal, with faster healing of wounds, less use of analgesics, reduced scarring, and exceptional cosmetic results regardless of the patients' age. The interaction of the energy of high-frequency radio wave signal interfaced with the electrode metal alloy causes a phenomenon called "Surface plasmon resonance." In order to improve the overall success and quality of radio wave surgery, Dr. Garito has long worked on the effects of high frequency radio wave energy on tissue. His first discovery was the introduction of the $4 \mathrm{MHz}$ Radio wave device. This discovery proved to be a major advance 


\section{Global Journal of Otolaryngology}

in surgical outcomes by greatly reducing the thermal effects of RF energy in tissue. He received a patent on this RF energy device in 1999. While experimenting with the RF electrodes, he discovered the difference in tissue response according to the size and shape of the RF electrodes and how they further reduced the thermal heat in tissue (Figure 1).

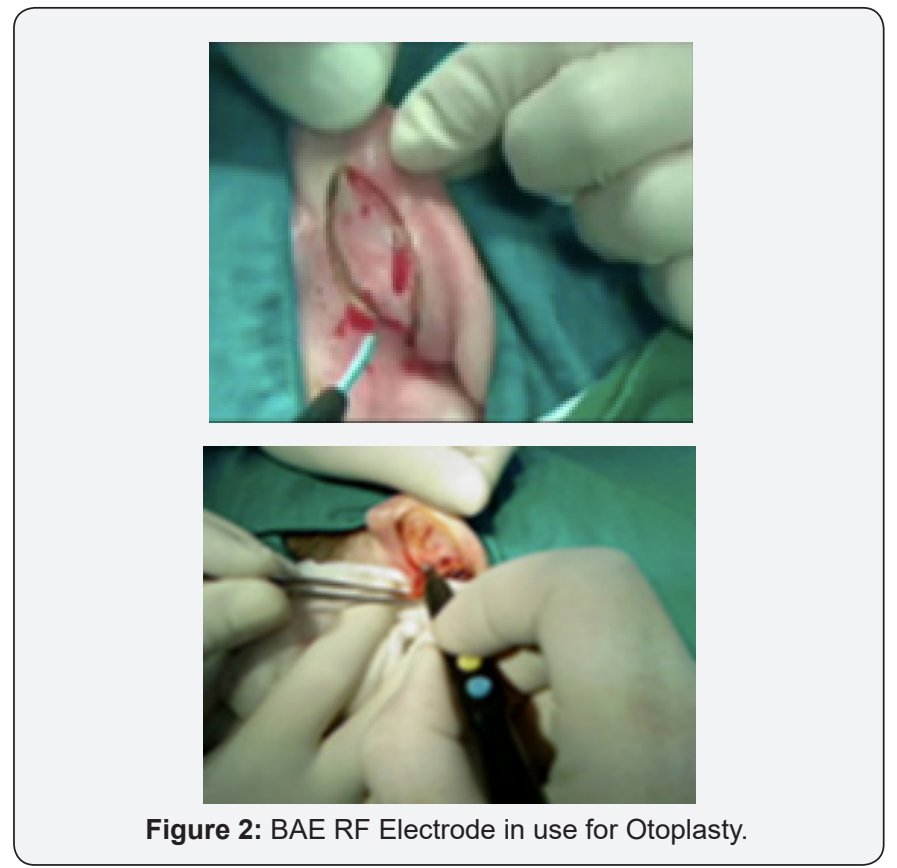

This led to the evaluation of different electrode metals, and how they can positively or negatively react with the RF Radio waves within the tissue. From there, Dr. Garito continued to innovate and improve the medical and technical quality of the $\mathrm{RF}$ electrodes themselves, thereby contributing further to better surgical outcomes. Dr. Garito hypothesized that, by raising the technical characteristics of the active RF electrode, he could produce a better match to the radio wave frequency. This modification would improve the performance and interaction of the RF Radio wave with the RF electrode throughout the surgical procedure. This is of course extremely meaningful for both the doctor and patient regarding available treatment options. He discovered that different alloys were better matches for the high frequency radio waves than others. Today, the Bio-Active Energy (BAE) RF electrode application represents a great improvement in RF technology, science and medicine, and in particular surgery. As for my own surgical practice, the BAE RF electrode now represents the "Gold Standard" of the twenty-first century. The quality of the active electrode, its design, and multiple other benefits will enable a physician to carry out a planned procedure with ease - --in addition to giving the patient a faster, more pain-free recovery with dramatically increased likelihood of aesthetic and cosmetic satisfaction. Although Electrosurgery and radio wave surgery have been in use for almost 30 years, little has been done since its introduction in the way of technical and medical improvement of the active electrode $\urcorner$, which is the key to the surgical application. By improving the technical characteristics, Dr. Garito has achieved a number of significant advantages that place this innovative BAE RF electrode at the pinnacle of RF electrodes. After numerous surgical procedures, I have concluded that radio wave surgery with this novel BAE RF electrode has vastly improved my surgical outcomes. The operative cut is much smoother and more precise, the scar is insignificant, the necrotic field is minimal, bleeding is controlled, the healing of the wound is faster and better, and swelling is reduced (Figure 2).

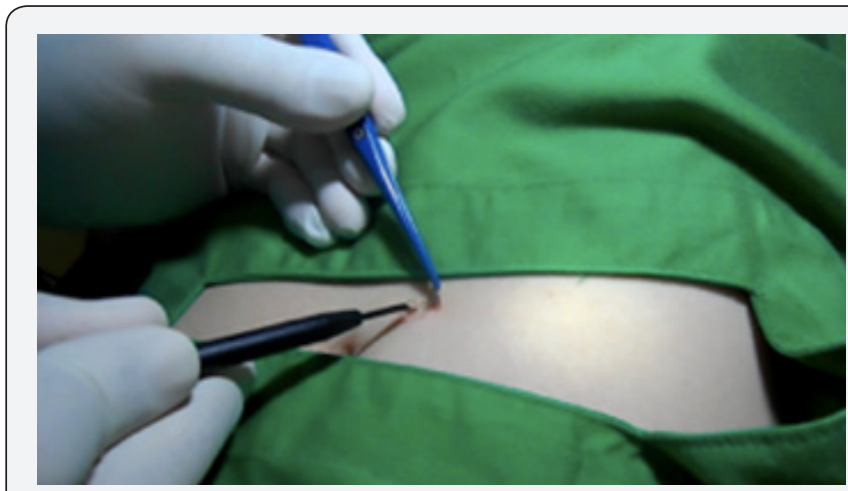

Figure 3: Excellent cosmetic results using the BAE RF Electrode in Dermatofibroma ablation procedure.

Multiple advantages exist with radio wave surgery when compared to other surgical techniques, the most significant being the ability to simultaneously cut and coagulate without significant lateral tissue damage. This lessens postsurgical pain and ensures faster healing (Figure 3).

a. Less lateral tissue damage

b. Minimal thermal lesion and bleeding

c. Smaller necrotic field

d. Less use of analgesics

e. Faster healing of wounds

f. Superior cosmetic results

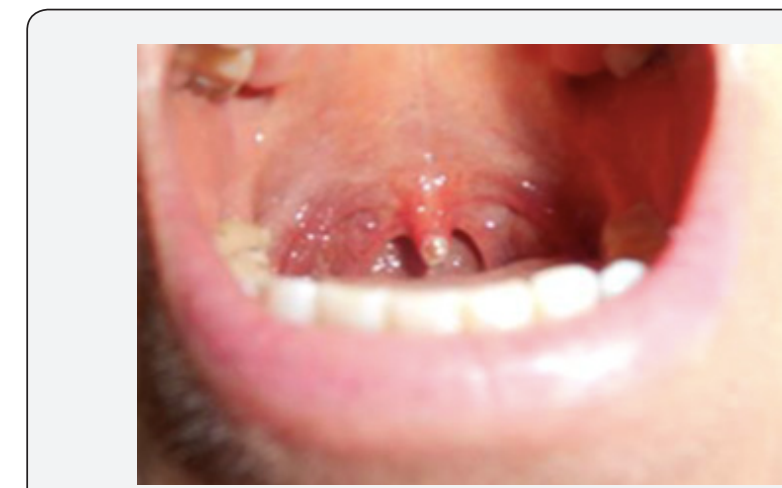

Figure 4: Three days post-Uvuloplasty using BAE RF Electrodes.

Another advantage is that a pressure-less incision can be performed with ease, even in deep and difficult to reach areas of tissues. The electrodes are reusable, and may be kept in cold sterilization solution when not in use. Use of radiofrequency in 
performance of various surgeries results in less trauma to the cells, less fibrous scarring, and less post-operative discomfort when compared to laser and electro-cautery surgery (Figure 4).

The results show that this technology has substantial advantages over techniques such as the scalpel, electrocauterizer, and lasers. The most important of these advantages are summarized below:

a. Ability to make an incision without using any pressure on the tissue

b. Submucosal interventions

c. Lesions can be layered to anatomic architecture

d. Active BAE RF electrode can be shaped according to any anatomical variations in the patient's treatment region

e. Biopsy taken with radio wave energy and BAE RF electrodes are comparable to the scalpel f. No danger from electro-shock or burning effect from passive electrode

g. Wide spectrum of use in various medical disciplines by adapting RF electrodes

h. Ideal for office, clinics, and ambulatory practices

Our surgical results show that high frequency $4 \mathrm{MHz}$ radio wave energy, combined and matched with certain noble metal alloys (BAE RF Electrodes), has great advantages over other surgical techniques such as a classic scalpel, electrosurgery, electrocautery, laser, and ultrasonic surgery. The most important of these are simultaneous cutting and coagulation, coagulation in liquid medium, minimal thermal damage of lateral tissues, and a faster healing of wound with excellent cosmetic results. In my opinion, if you want surgery without thermal heat, incisions without scarring, and superior cosmetic results - High Frequency $4 \mathrm{MHz}$ Radio waves and BAE RF electrodes are the clear and optimal choice.

\section{Your next submission with Juniper Publishers will reach you the below assets}

- Quality Editorial service

- Swift Peer Review

- Reprints availability

- E-prints Service

- Manuscript Podcast for convenient understanding

- Global attainment for your research

- Manuscript accessibility in different formats

( Pdf, E-pub, Full Text, Audio)

- Unceasing customer service

Track the below URL for one-step submission https://juniperpublishers.com/online-submission.php 